\title{
The Role of Core Needle Biopsy for Thyroid Nodules with Initially Indeterminate Results on Previous Fine-Needle Aspiration: A Systematic Review and Meta-Analysis
}

\author{
(D) C.H. Suh, (D).H. Baek, (D) C. Park, (D).J. Choi, and (D).H. Lee
}

\begin{abstract}
BACKGROUND: Sonography-guided fine-needle aspiration leads to relatively frequent cases of indeterminate cytology for the diagnosis of thyroid nodules.

PURPOSE: Our aim was to evaluate the efficacy and safety of core needle biopsy for the examination of thyroid nodules with initially indeterminate results on fine-needle aspiration.

DATA SOURCES: A computerized search of the MEDLINE and Embase databases was performed to identify relevant original articles.

STUDY SELECTION: Studies investigating the use of core needle biopsy for thyroid nodules with initially indeterminate results on previous fine-needle aspiration were eligible for inclusion.

DATA ANALYSIS: The pooled proportions for nondiagnostic results, inconclusive results, malignancy on core needle biopsy, the ability of core needle biopsy to diagnose malignancy, and the related complications of the procedure were analyzed.

DATA SYNTHESIS: The meta-analytic pooling was based on a random-effects model. Nine eligible studies, involving 2240 patients with 2245 thyroid nodules, were included. The pooled proportion for nondiagnostic results was $1.8 \%(95 \% \mathrm{Cl}, 0.4 \%-3.2 \%)$, and the pooled proportion for inconclusive results was $25.1 \%(95 \% \mathrm{Cl}, 15.4 \%-34.9 \%)$. The pooled proportion for malignancy was $18.9 \%(95 \% \mathrm{Cl}, 8.4 \%-29.5 \%)$. With regard to the diagnostic performance for malignancy, the sensitivity of core needle biopsy varied, ranging from $44.7 \%$ to $85.0 \%$, but the specificity was $100 \%$ in all cases. No major complications of core needle biopsy were observed.
\end{abstract}

LIMITATIONS: The relatively small number of included studies and retrospective nature were limitations.

CONCLUSIONS: Core needle biopsy has low nondiagnostic result rates and high specificity for the diagnosis of malignancy. It is a safe diagnostic technique with a higher diagnostic yield, especially when molecular testing is not available or fine-needle aspiration did not yield enough cells for molecular testing.

ABBREVIATIONS: AUS = atypia of undetermined significance; $C N B=$ core needle biopsy; FLUS $=$ follicular lesion of undetermined significance; FNA $=$ fine-needle aspiration; US = ultrasound

S onography (US)-guided fine-needle aspiration (FNA) is an accurate and safe technique for the diagnosis of thyroid nodules. However, FNA leads to relatively frequent indeterminate cytology. ${ }^{1,2}$ According to the 2015 American Thyroid Association Management Guidelines, repeat FNA or molecular testing may be used to supplement the malignancy risk assessment of thyroid nodules with cytology findings of atypia of undetermined significance (AUS)/follicular lesion of undetermined significance

Received November 21, 2016; accepted after revision February 13, 2017. From the Department of Radiology and Research Institute of Radiology (C.H.S., J.H.B.,Y.J.C., J.H.L.), University of Ulsan College of Medicine, Asan Medical Center, Seoul, Republic of Korea; Department of Radiology (C.H.S., C.P.), Namwon Medical Center, Jeollabuk-Do, Republic of Korea; and Department of Radiology (C.P.), Chonnam National University Hospital, Gwangju, Republic of Korea.
(FLUS). ${ }^{3}$ Moreover, if repeat FNA or molecular testing findings are deemed inconclusive, either surveillance or a diagnostic operation may be performed, given certain clinical risk factors, US patterns, and patient preferences. ${ }^{3}$ Nevertheless, repeat FNA has reportedly high rates of nondiagnostic $(6.9 \%-9.9 \%)$ or inconclusive results $(19.2 \%-52.5 \%)$ in the examination of thyroid nodules with initially indeterminate results on previous FNA. ${ }^{4-8}$

Please address correspondence to Jung Hwan Baek, MD, PhD, Department of Radiology and Research Institute of Radiology, University of Ulsan College of Medicine, Asan Medical Center, 86 Asanbyeongwon-Gil, Songpa-Gu, Seoul 138-736, Republic of Korea; e-mail: radbaek@naver.com

三 Indicates article with supplemental on-line table.

Indicates article with supplemental on-line photos.

http://dx.doi.org/10.3174/ajnr.A5182

AJNR Am J Neuroradiol 38:1421-26 Jul 2017 www.ajnr.org 
Several recent studies have reported the advantages of using core needle biopsy (CNB) for the examination of thyroid nodules with initially indeterminate results on previous FNA. ${ }^{6-14} \mathrm{CNB}$ has been reported to have low rates of nondiagnostic $(0.5 \%-3.8 \%)$ and inconclusive $(9.1 \%-45.3 \%)$ results compared with the inconclusive results of FNA (19.2\%-52.5\%). 6,7,9,11,12,14 However, some physicians remain skeptical of the use of CNB for the examination of thyroid nodules with initially indeterminate results on previous FNA because most research has included observational or descriptive studies with small sample sizes. Furthermore, the American Thyroid Association guidelines do not recommend the routine use of $\mathrm{CNB}$, possibly because of the high associated morbidity rates and the limited evidence elucidated thus far. ${ }^{3}$ Hence, it is essential to collect and review the currently available data regarding the prevalence of nondiagnostic results, diagnostic performance, and complications of CNB for the examination of thyroid nodules with initially indeterminate results on previous FNA.

To our knowledge, no studies have generated a comprehensive systematic summary of cases of thyroid nodules with initially indeterminate results on previous FNA. Accordingly, we aimed to systematically review the published literature and evaluate the prevalence of nondiagnostic results, diagnostic performance, and complications of CNB for thyroid nodules with initially indeterminate results on previous FNA, which could provide additional data to support standardized management of these lesions.

\section{MATERIALS AND METHODS}

\section{Literature Search Strategy}

A computerized search of the MEDLINE and Embase databases was performed to identify relevant original articles on the use of $\mathrm{CNB}$ for examining thyroid nodules with initially indeterminate results on previous FNA until May 15, 2016. We used the following search terms: (thyroid) AND (core-needle biopsy OR core needle biopsy OR CNB) AND (Bethesda category 3 OR atypia of undetermined significance OR AUS OR follicular lesion of undetermined significance OR FLUS OR indeterminate OR inconclusive). Our search was limited to English-language studies. The bibliographies of the selected articles were screened to identify other relevant articles.

\section{Inclusion Criteria}

Studies investigating the use of CNB for thyroid nodules with initially indeterminate results on previous FNA were eligible for inclusion. However, we included only studies that fulfilled all of the following criteria:

1) Population. Patients with thyroid nodules who underwent $\mathrm{CNB}$ evaluations following initially indeterminate results on previous FNA.

2) Reference Standard. Because the diagnostic criteria for CNB of thyroid nodules have not been standardized, the histologic results of $\mathrm{CNB}$ were grouped into the 6 categories of the Bethesda System ${ }^{6,9,15}$ : nondiagnostic results, benign, AUS or FLUS, follicular neoplasm or suspicious for follicular neoplasm, suspicious for malignancy, and malignant. ${ }^{16}$ We defined indeterminate results as those that at least fulfilled the criteria of thyroid nodules with Bethesda category 3 (AUS and FLUS), including cases with atypical cells that could not be diagnosed as "suspicious for malignancy" or "malignancy," or those with cellular follicular nodules that could not be diagnosed as "follicular neoplasm" or "suspicious for follicular neoplasm.” The malignant nodules were diagnosed after an operation or biopsy. In contrast, benign nodules were diagnosed after an operation, in cases in which at least 2 sets of benign findings were noted on FNA and/or CNB, or in cases in which benign cytology findings were noted on FNA or CNB and the nodule size remained stable after 1 year.

3) Outcomes. Results that were sufficiently detailed to evaluate the prevalence of nondiagnostic results, diagnostic performance, and complications of CNB.

\section{Exclusion Criteria}

The exclusion criteria were as follows: 1) case reports and case series with a sample size of $<10 ; 2$ ) review articles, editorials, letters, comments, and conference proceedings; 3 ) studies that did not focus on the use of CNB for thyroid nodules with initially indeterminate results on previous FNA; and 4) studies with partially overlapping patients and data. Two reviewers (C.H.S. and J.H.B.) independently selected the literature reports with a standardized form.

\section{Data Extraction}

These data were extracted from each of the following studies and entered into standardized data forms: 1) authors, year of publication, hospital or medical school, years of patient recruitment, study design, and sample size; 2) mean age, nodule size, and patient reference standards; 3 ) rates of nondiagnostic results, inconclusive results, and malignancy; 4) diagnostic performance of CNB for malignancy; and 5) complications, the size of the core needle, and patient anticoagulation status. One reviewer (C.H.S.) extracted the data from the studies, and the second reviewer (J.H.B.) confirmed the accuracy of the extracted data. There were a few disagreements, which were resolved by a unanimous decision.

\section{Quality Assessment}

The quality of the included studies was analyzed independently by 2 reviewers (C.H.S. and J.H.B.) with customized questionnaires based on the Quality Assessment of Diagnostic Accuracy Studies-2 (QUADAS-2) criteria. ${ }^{17}$ Very few disagreements were noted, which were resolved by consensus.

\section{Data Synthesis and Statistical Analysis}

The pooled proportions for the nondiagnostic results, inconclusive results, and malignancy on CNB following initially indeterminate results on previous FNA were adopted as the primary indices. The meta-analytic pooling was based on the inverse variance method for calculating weights, and the pooled proportions and their $95 \%$ confidence intervals were determined by using the DerSimonian-Laird random-effects model. ${ }^{18-20}$ Heterogeneity among the studies was determined by using following methods: The Cochran Q-test was performed for the pooled estimates with $P<.05$ indicating heterogeneity. In addition, we performed the Higgins inconsistency index $\left(\mathrm{I}^{2}\right)$ test: $0 \%-40 \%$, might not be important; $30 \%-60 \%$, may represent moderate heterogeneity; 
50\%-90\%, may represent substantial heterogeneity; and 75\%$100 \%$, may represent considerable heterogeneity. ${ }^{21,22}$ The publication biases were visually assessed by using funnel plots. Thereafter, publication bias-adjusted pooled estimates - that is, adjusted pooled proportions — were obtained by using the trimand-fill method. ${ }^{23}$ If the original unadjusted pooled proportions and the trim-and-fill-adjusted pooled proportions were in agreement, the results were regarded as robust for publication bias.

The secondary indices of this study included the diagnostic performance of $\mathrm{CNB}$ for malignancy and complications. We estimated the descriptive statistics for the diagnostic performance of $\mathrm{CNB}$, including sensitivity, specificity, positive predictive value, and negative predictive value. All statistical analyses were performed by using R statistical and computing software, Version 3.0.2 (http://www.r-project.org/) with the "metafor" and "mada" packages.

\section{RESULTS}

\section{Literature Search}

The study selection process is illustrated in Fig 1. A literature search of the Ovid MEDLINE and Embase databases identified 105 articles; after we removed the duplicates, 77 articles were screened for eligibility. Of those, 64 were excluded after a review of their titles and abstracts, including 35 review articles; 12 case reports; 9 letters, editorials, or conference abstracts; and 8 articles not related to the topic of interest of this study. The full texts of the remaining 13 articles were reviewed; a search of their bibliographies found no additional eligible studies. Of these 13 articles, 4 were further excluded after reviewing their full texts, due to the presence of partially overlapping patient cohorts. ${ }^{24-27}$ Finally, 9

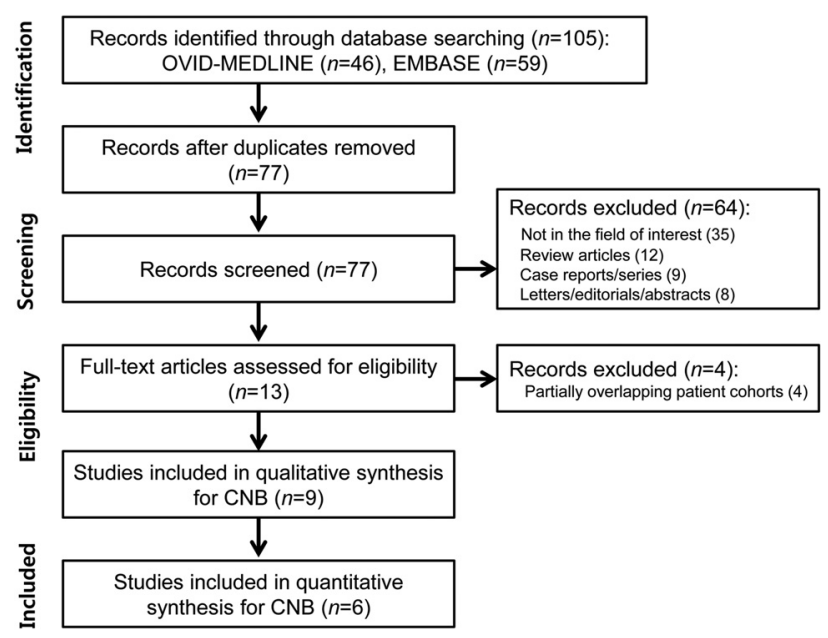

FIG 1. Flow diagram of the study selection process. eligible studies, involving 2240 patients with 2245 thyroid nodules, were included in this meta-analysis. ${ }^{6-14}$

\section{Characteristics of the Included Studies}

The detailed characteristics of the 9 included studies are summarized in the On-line Table. All the included studies were retrospective in nature. The mean patient age ranged from 46 to 54.1 years. Of the 9 studies, only CNB was performed for the thyroid nodules in $6,{ }^{9-14}$ whereas both $\mathrm{CNB}$ and repeat FNA were performed in $3 .^{6-8}$ Among the studies, 2 included patients who simultaneously underwent repeat FNA and $\mathrm{CNB}$ of each nodule, wherein repeat FNA was performed before CNB. ${ }^{6,7}$ In those studies, real-time US guidance was used to determine that the CNB and repeat FNA were focusing on the same nodule. In 8 studies, the size of the core needle was 18 ga; 1 study was not explicit. ${ }^{13}$

The inclusion of thyroid nodules was slightly heterogeneous among the studies. Five studies included thyroid nodules with initial AUS or FLUS results at previous FNA, ${ }^{6,7,9,12,14}$ whereas Jang et $\mathrm{al}^{11}$ included nodules with initial AUS results at previous FNA. Moreover, Trimboli et $\mathrm{al}^{13}$ included nodules with initial AUS or FLUS or follicular neoplasm/suspicious for follicular neoplasm results at previous FNA. Hahn et $\mathrm{al}^{10}$ included nodules with initial inconclusive results at previous FNA, and Park et $\mathrm{al}^{8}$ included initially indeterminate nodules at previous FNA. Hence, we finally included 6 studies (1836 nodules) that examined nodules with initial AUS or FLUS results at previous FNA in the quantitative synthesis of our meta-analysis. ${ }^{6,7,9,11,12,14}$ Among these 6 studies, 4 (496 nodules) included assessments of the diagnostic performance of thyroid malignancy. ${ }^{6,7,9,14}$ Two studies were excluded due to the presence of insufficient data for creating the diagnostic 2-by-2 table for CNB. ${ }^{11,12}$ The quality of the included studies, as assessed by the QUADAS-2 tool, was moderate overall, with all the studies satisfying $\geq 5$ of the 7 items (On-line Fig 1). ${ }^{17}$

\section{Prevalence of Nondiagnostic Results, Inconclusive Results, and Malignancy of CNB}

Among the 6 studies included, 1836 nodules with initial AUS or FLUS results at previous FNA were examined. The pooled proportions for nondiagnostic results, inconclusive results, and malignancy on CNB are summarized in the Table, and the corresponding forest plots are shown in Fig 2. The pooled proportion for nondiagnostic results was $1.8 \%$ (95\% CI, $0.4 \%-3.2 \%)$, and the pooled proportion for inconclusive results was $25.1 \%$ (95\% CI, $15.4 \%-34.9 \%)$. The pooled proportion for malignancy was $18.9 \%$ (95\% CI, 8.4\%-29.5\%). Considerable heterogeneity was observed among the studies in terms of the pooled proportions on CNB $\left(I^{2}=94.6 \%-98.3 \%\right)$. The funnel plots showed a publication bias for the pooled proportion for nondiagnostic results and ma-

Summary of the meta-analytic pooled proportions for nondiagnostic results, inconclusive results, and malignancy on CNB

\begin{tabular}{|c|c|c|c|c|c|c|c|}
\hline & \multirow[b]{2}{*}{$\begin{array}{l}\text { No. of } \\
\text { Studies }\end{array}$} & \multirow[b]{2}{*}{$\begin{array}{l}\text { Total No. } \\
\text { of Cases }\end{array}$} & \multicolumn{3}{|c|}{ Summary Estimate } & \multicolumn{2}{|c|}{ Trim-and-Fill Estimate } \\
\hline & & & $\begin{array}{l}\text { Pooled Proportion } \\
\qquad(95 \% \mathrm{Cl})\end{array}$ & $\begin{array}{c}P \text { Value for } \\
\text { Heterogeneity }\end{array}$ & $\mathrm{I}^{2 \mathrm{~b}}$ & $\begin{array}{c}\text { No. of } \\
\text { Missing Studies }\end{array}$ & $\begin{array}{l}\text { Adjusted Pooled } \\
\text { Proportion }(95 \% \mathrm{Cl})\end{array}$ \\
\hline Nondiagnostic results & 6 & 1836 & $1.8 \%(0.4 \%-3.2 \%)$ & $<.01$ & $94.6 \%$ & 2 & $0.8 \%(-0.8 \%-2.5 \%)$ \\
\hline Inconclusive results & 6 & 1836 & $25.1 \%(15.4 \%-34.9 \%)$ & $<.01$ & $95.8 \%$ & 0 & \\
\hline Malignancy & 6 & 1836 & $18.9 \%(8.4 \%-29.5 \%)$ & $<.01$ & $98.3 \%$ & 1 & $15.6 \%(4.4 \%-26.8 \%)$ \\
\hline
\end{tabular}

a $P$ value by the Cochran $Q$ method to test the heterogeneity of the pooled data, with $P<.05$ indicating substantial heterogeneity.

${ }^{b}$ Higgins index for heterogeneity $(0 \%-40 \%$, might not be important; $30 \%-60 \%$, may represent moderate heterogeneity; $50 \%-90 \%$, may represent substantial heterogeneity; $75 \%-100 \%$, may represent considerable heterogeneity). 
Pooled Proportion

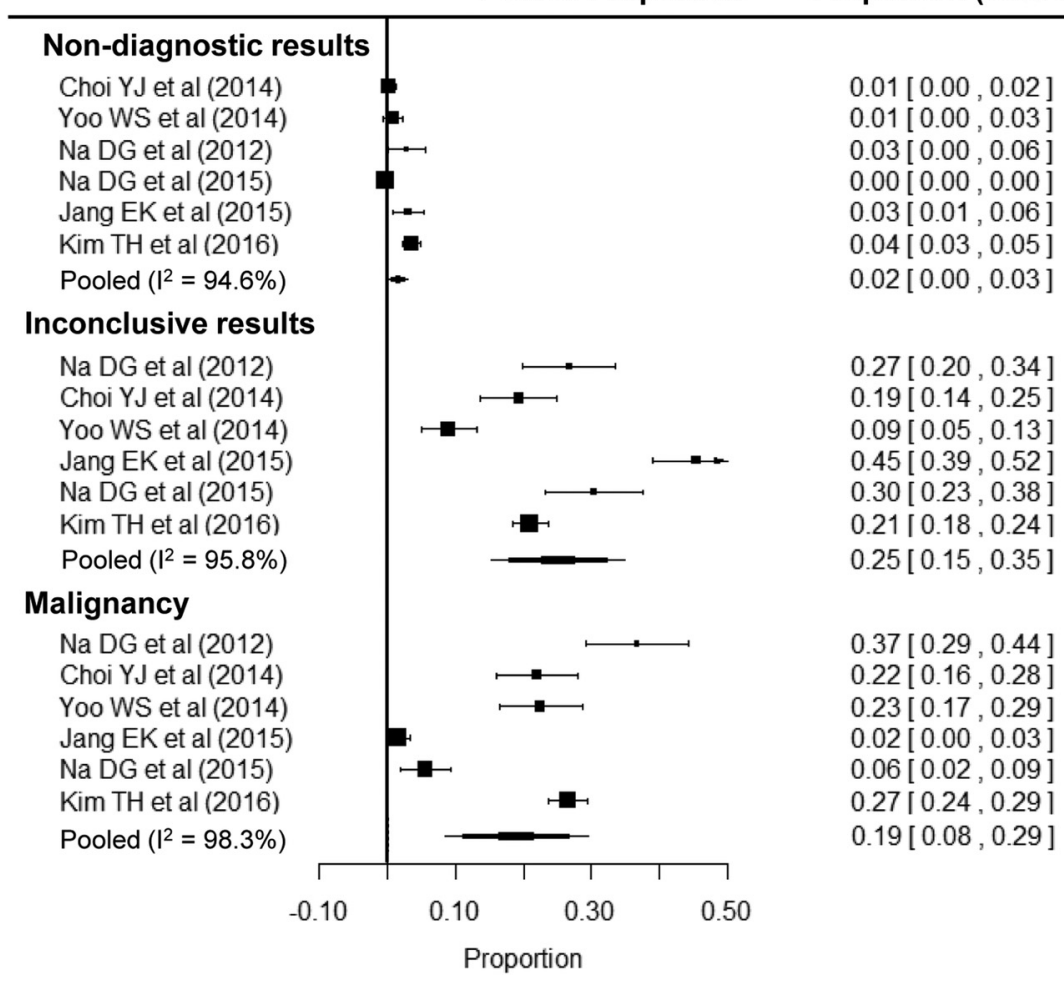

FIG 2. Forest plots for nondiagnostic results, inconclusive results, and malignancy of the CNB. Numbers are pooled estimates with $95 \%$ confidence intervals in parentheses. Horizontal lines indicate $95 \% \mathrm{Cls}$, and the black box on each line indicates the standardized mean difference for each study. The black diamond at the bottom of the plot shows the average effect size of the included studies.

lignancy on CNB (On-line Fig 2). After we adjusted for publication bias with the trim-and-fill approach, the adjusted pooled proportion for nondiagnostic results was $0.8 \%$ (95\% CI, $-0.8 \%-$ $2.5 \%)$ and the adjusted pooled proportion for malignancy was $15.6 \%$ (95\% CI, 4.4\%-26.8\%), which were in agreement with the unadjusted pooled estimates.

\section{Diagnostic Performance of CNB for Malignancy}

The diagnostic performance of $\mathrm{CNB}$ for malignancy was described in 4 studies involving 496 nodules. The diagnostic criteria for malignancy included a classification of Bethesda category 6 (malignancy). Pooling was not performed due to the relatively small number of studies included, the high risk of bias, and the inherent heterogeneity based on various study designs. The sensitivity varied from $44.7 \%$ to $85.0 \%$; in fact, the lower margin of the $95 \%$ CI reached $25.2 \%$. Nevertheless, the specificity was consistent, and all studies indicated a specificity of $100 \%$; in fact, the lower margin of the $95 \%$ CI reached $89.1 \%$. The positive predictive values were also consistent (100\% in all 4 studies), whereas the negative predictive values varied $(65.0 \%, 88.0 \%, 88.1 \%$, and $94.0 \%)$.

\section{Complications}

Six of the 9 studies reported on the complications of CNB. ${ }^{6-10,12}$ In these 6 studies, no major complications, procedure-related deaths, or need for hospital admission or intervention was reported. One study reported a case (1/191) of neck swelling, pain, and perithyroid hematoma, ${ }^{9}$ whereas another study reported the occurrence of minor complications, including small perithyroid hematomas in 8 patients $(8 / 220)$ and mild transient parenchymal edema in 5 patients $(5 / 220)$. All these patients had undergone simultaneous CNB and repeat FNA for each nodule in that study. ${ }^{6}$ They used 18 -ga needles for CNB and 21-, 23-, or 25-ga needles for FNA. In case of patients receiving antiplatelet therapy, procedures were performed after discontinuing these medications for 1 week.

\section{DISCUSSION}

We performed a systematic review and meta-analysis to evaluate the efficacy and complications of CNB in the examination of thyroid nodules with initially indeterminate results on previous FNA. In the present study, we found that the pooled proportion for nondiagnostic results was $1.8 \%(95 \% \mathrm{CI}, 0.4 \%-3.2 \%)$; for inconclusive results, it was $25.1 \%$ (95\% CI, 15.4\%-34.9\%); and for malignancy, it was $18.9 \%$ (95\% CI, $8.4 \%$ $29.5 \%$ ). With regard to the diagnostic performance for malignancy, the sensitivity of $\mathrm{CNB}$ varied from $44.7 \%$ to $85.0 \%$, but the specificity was constant at $100 \%$. There were no major complications associated with CNB. Considering these findings, CNB is a safe diagnostic technique with higher diagnostic yield, especially when molecular testing is not available or FNA does not yield enough cells for molecular testing.

Several studies have reported that CNB is useful for evaluating thyroid nodules with initial "nondiagnostic results" on previous FNA. ${ }^{15,28,29}$ A recent meta-analysis demonstrated that CNB may serve as a complementary diagnostic technique for thyroid nodules with initial nondiagnostic results on previous FNA, including 4 studies. ${ }^{30}$ Currently, the definite diagnosis and management of thyroid nodules with initially "indeterminate results" on previous FNA are commonly encountered problems in daily clinical practice. Therefore, we performed this systematic review and metaanalysis of thyroid nodules with initially indeterminate FNA results, including 9 studies. In the present study, CNB demonstrated low nondiagnostic result rates $(1.8 \%$; 95\% CI, $0.4 \%-3.2 \%)$ and high specificities (100\%) in the diagnosis of malignancy. The Korean Society of Thyroid Radiology guidelines mentioned that CNB might be useful for obtaining conclusive results in cases of thyroid nodules with initially indeterminate results on previous FNA. ${ }^{31,32}$ We believe that consistent evidence favoring the use of $\mathrm{CNB}$, including the results of our systematic review with a metaanalysis, may be considered as a subsequent diagnostic approach for thyroid nodules with initially indeterminate results on previous FNA.

A gene-expression classifier is a molecular assay that was developed to improve surgical decision-making in cases of thyroid 
nodules with initially indeterminate results on previous FNA. A previous prospective multicenter study reported on the ability of a gene-expression classifier to correctly identify indeterminate nodules (AUS/FLUS), with high sensitivity and negative predictive values (90\% and 94\%-95\%, respectively) but low specificity (53\%). ${ }^{32}$ In our present study, the specificities were $100 \%$ and the negative predictive values were variable, ranging from $65.0 \%$ to $94.0 \%$. Moreover, a recent interinstitutional validation study showed that there were wide variations in the performance of the gene-expression classifier. ${ }^{33}$ The cost of the gene-expression classifier is also high. Hence, although CNB shows slightly lower negative predictive values compared with those of the gene-expression classifier, CNB may serve as a better alternative method, with higher specificities and lower cost, in institutions in which the gene-expression classifier is not available.

$\mathrm{CNB}$ is reportedly more effective at obtaining large tissue samples, which enable molecular testing for the accurate diagnosis and assessment of the histologic architecture. Several recent articles have reported on molecular testing, which can be used for identification in CNB specimens of thyroid nodules with initially indeterminate results on previous FNA. ${ }^{11,12,24,27}$ Choi et $\mathrm{al}^{24}$ revealed that the combination of BRAF V600E mutation analysis and CNB may add further value to the examination of thyroid nodules with initial AUS results on previous FNA. Furthermore, Kim et al ${ }^{12}$ suggested a simple triage scheme involving US findings, $\mathrm{CNB}$, or BRAF V600E mutation analysis, which can be used to identify a subpopulation of patients with a low or high likelihood of thyroid cancer among those with thyroid nodules with initial AUS/FLUS results on previous FNA. Jang et $\mathrm{al}^{11}$ demonstrated that NRAS codon 61 mutation analysis along with CNB could be useful for achieving a clinical decision in cases of thyroid nodules with initial AUS results on previous FNA. Moreover, Trimboli et $\mathrm{al}^{27}$ reported that galectin-3 and HBME-1 could improve the accuracy of $\mathrm{CNB}$ in cases of thyroid nodules with initially indeterminate results on previous FNA. Hence, it would be ideal for CNB to be integrated with radiologic, cytopathologic, or histologic approaches, along with certain patient factors, to optimize patient management. Moreover, further studies on longterm outcome data would help prove its clinical utility.

In our current systematic review, we did not observe any major complications of CNB. However, 1 case exhibited minor complications (1/191), including swelling, pain, and perithyroid hematomas after the $\mathrm{CNB}$ procedure. ${ }^{9} \mathrm{CNB}$ is known to be a safe, well-tolerated method and is associated with a low complication rate. ${ }^{34}$ Modern spring-activated biopsy needles (18-22 gauge) and US guidance can now be used to achieve high diagnostic accuracy and low complication rates. Despite such advances, CNB should be performed carefully under US guidance by experienced operators who are familiar with the US anatomy of the thyroid gland and perithyroid areas. ${ }^{30,31,35}$

Our meta-analysis had several limitations of note. First, there were several inherent limitations of our study - that is, the relatively small number of included studies and its retrospective nature. Therefore, this meta-analysis should be interpreted cautiously if one wants to apply the findings. However, we used validated systematic review methods and reported results according to the standard reporting guidelines: the Preferred Reporting
Items for Systematic Reviews and Meta-Analyses ${ }^{36}$ and the guidelines of the Handbook for Diagnostic Test Accuracy Reviews published by the Cochrane Collaboration. ${ }^{37}$ Second, our metaanalysis showed considerable heterogeneity in the pooled proportions. These heterogeneities were possibly due to the technical variation among the institutions or operators, the nodule characteristics, the number of passes, or the absence of standardized pathologic criteria for CNB. Third, a comparison of diagnostic performance between $\mathrm{CNB}$ and repeat FNA could not be performed. Repeat FNA also provides definitive categorization of indeterminate nodules. ${ }^{38}$ Fourth, the prevalence of malignancy in patients with nondiagnostic/indeterminate thyroid nodules and the mortality of thyroid cancer remains low. Therefore, the clinical impact of the observed higher conclusive results of CNB compared with repeat FNA could be controversial. ${ }^{39,40}$

\section{CONCLUSIONS}

This systematic review and meta-analysis indicate that CNB has low nondiagnostic result rates and high specificities for the diagnosis of malignancy. CNB is a safe diagnostic technique with higher diagnostic yield, especially when molecular testing is not available or FNA did not yield enough cells for molecular testing.

\section{REFERENCES}

1. Baier ND, Hahn PF, Gervais DA, et al. Fine-needle aspiration biopsy of thyroid nodules: experience in a cohort of 944 patients. $A J R A m J$ Roentgenol 2009;193:1175-79 CrossRef Medline

2. Wang CC, Friedman L, Kennedy GC, et al. A large multicenter correlation study of thyroid nodule cytopathology and histopathology. Thyroid 2011;21:243-51 CrossRef Medline

3. Haugen BR, Alexander EK, Bible KC, et al. 2015 American Thyroid Association Management Guidelines for Adult Patients with Thyroid Nodules and Differentiated Thyroid Cancer: The American Thyroid Association Guidelines Task Force on Thyroid Nodules and Differentiated Thyroid Cancer. Thyroid 2016;26:1-133 CrossRef Medline

4. Yassa L, Cibas ES, Benson CB, et al. Long-term assessment of a multidisciplinary approach to thyroid nodule diagnostic evaluation. Cancer 2007;111:508-16 CrossRef Medline

5. Nayar R, Ivanovic M. The indeterminate thyroid fine-needle aspiration: experience from an academic center using terminology similar to that proposed in the 2007 National Cancer Institute Thyroid Fine Needle Aspiration State of the Science Conference. Cancer 2009;117:195-202 Medline

6. Na DG, Kim JH, Sung JY, et al. Core-needle biopsy is more useful than repeat fine-needle aspiration in thyroid nodules read as nondiagnostic or atypia of undetermined significance by the Bethesda system for reporting thyroid cytopathology. Thyroid 2012;22:468-75 CrossRef Medline

7. Na DG, Min HS, Lee H, et al. Role of core needle biopsy in the management of atypia/follicular lesion of undetermined significance thyroid nodules: comparison with repeat fine-needle aspiration in subcategory nodules. Eur Thyroid J 2015;4:189-96 CrossRef Medline

8. Park KT, Ahn SH, Mo JH, et al. Role of core needle biopsy and ultrasonographic finding in management of indeterminate thyroid nodules. Head Neck 2011;33:160-65 CrossRef Medline

9. Choi YJ, Baek JH, Ha EJ, et al. Differences in risk of malignancy and management recommendations in subcategories of thyroid nodules with atypia of undetermined significance or follicular lesion of undetermined significance: the role of ultrasound-guided coreneedle biopsy. Thyroid 2014;24:494-501 CrossRef Medline

10. Hahn SY, Shin JH, Han BK, et al. Ultrasonography-guided core needle biopsy for the thyroid nodule: does the procedure hold any ben-

AJNR Am J Neuroradiol 38:1421-26 Jul 2017 www.ajnr.org 
efit for the diagnosis when fine-needle aspiration cytology analysis shows inconclusive results? Br J Radiol 2013;86:20130007 CrossRef Medline

11. Jang EK, Kim WG, Kim EY, et al. Usefulness of NRAS codon 61 mutation analysis and core needle biopsy for the diagnosis of thyroid nodules previously diagnosed as atypia of undetermined significance. Endocrine 2016;52:305-12 CrossRef Medline

12. Kim TH, Jeong DJ, Hahn SY, et al. Triage of patients with AUS/FLUS on thyroid cytopathology: effectiveness of the multimodal diagnostic techniques. Cancer Med 2016;5:769-77 CrossRef Medline

13. Trimboli P, Nasrollah N, Amendola S, et al. A cost analysis of thyroid core needle biopsy vs. diagnostic surgery. Gland Surg 2015;4:307-11 CrossRef Medline

14. Yoo WS, Choi HS, Cho SW, et al. The role of ultrasound findings in the management of thyroid nodules with atypia or follicular lesions of undetermined significance. Clin Endocrinol (Oxf) 2014;80: 735-42 CrossRef Medline

15. Yeon JS, Baek JH, Lim HK, et al. Thyroid nodules with initially nondiagnostic cytologic results: the role of core-needle biopsy. Radiology 2013;268:274-80 CrossRef Medline

16. Cibas ES, Ali SZ. The Bethesda System for Reporting Thyroid Cytopathology. Am J Clin Pathol 2009;132:658-65 CrossRef Medline

17. Whiting PF, Rutjes AW, Westwood ME et al. QUADAS-2: a revised tool for the quality assessment of diagnostic accuracy studies. Ann Intern Med 2011;155:529-36 CrossRef Medline

18. Suh $\mathrm{CH}$, Park SH. Successful publication of systematic review and meta-analysis of studies evaluating diagnostic test accuracy. Korean J Radiol 2016;17:5-6 CrossRef Medline

19. Kim KW, Lee J, Choi SH, et al. Systematic review and meta-analysis of studies evaluating diagnostic test accuracy-a practical review for clinical researchers, part I: general guidance and tips. Korean J Radiol 2015;16:1175-87 CrossRef Medline

20. Lee J, Kim KW, Choi SH, et al. Systematic review and meta-analysis of studies evaluating diagnostic test accuracy-a practical review for clinical researchers, part II: statistical methods of meta-analysis. Korean J Radiol 2015;16:1188-96 CrossRef Medline

21. Higgins J, Green S. Cochrane Handbook for Systematic Reviews of Interventions. Version 5.1.0. Updated March 2011. The Cochrane Collaboration. http://handbook.cochrane.org. Accessed August 15, 2015

22. Higgins JP, Thompson SG, Deeks JJ, et al. Measuring inconsistency in meta-analyses. BMJ 2003;327:557-60 CrossRef Medline

23. Duval S, Tweedie R. Trim and fill: a simple funnel-plot-based method of testing and adjusting for publication bias in meta-analysis. Biometrics 2000;56:455-63 CrossRef Medline

24. Choi SH, Baek JH, Lee JH, et al. Evaluation of the clinical usefulness of BRAFV600E mutation analysis of core-needle biopsy specimens in thyroid nodules with previous atypia of undetermined significance or follicular lesions of undetermined significance results. Thyroid 2015;25:897-903 CrossRef Medline

25. Lee $\mathrm{KH}$, Shin JH, Oh YL, et al. Atypia of undetermined significance in thyroid fine-needle aspiration cytology: prediction of malignancy by US and comparison of methods for further management. Ann Surg Oncol 2014;21:2326-31 CrossRef Medline

26. Nasrollah N, Trimboli P, Guidobaldi L, et al. Thin core biopsy should help to discriminate thyroid nodules cytologically classi- fied as indeterminate: a new sampling technique. Endocrine 2013; 43:659-65 CrossRef Medline

27. Trimboli P, Guidobaldi L, Amendola S, et al. Galectin-3 and HBME-1 improve the accuracy of core biopsy in indeterminate thyroid nodules. Endocrine 2016;52:39-45 CrossRef Medline

28. Suh $\mathrm{CH}$, Baek JH, Lee JH, et al. The role of core-needle biopsy in the diagnosis of thyroid malignancy in 4580 patients with 4746 thyroid nodules: a systematic review and meta-analysis. Endocrine 2016;54: 315-28 CrossRef Medline

29. Suh $\mathrm{CH}, \mathrm{Baek} \mathrm{JH}, \mathrm{Kim} \mathrm{KW}$, et al. The role of core-needle biopsy for thyroid nodules with initially nondiagnostic fine-needle aspiration results: a systematic review and meta-analysis. Endocr Pract 2016;22: 679-88 CrossRef Medline

30. Lee YH, Baek JH, Jung SL, et al; Korean Society of Thyroid Radiology (KSThR), Korean Society of Radiology. Ultrasound-guided fine needle aspiration of thyroid nodules: a consensus statement by the Korean Society of Thyroid Radiology. Korean J Radiol 2015;16:391-401 CrossRef Medline

31. Shin JH, Baek JH, Chung J, et al; Korean Society of Thyroid Radiology (KSThR) and Korean Society of Radiology. Ultrasonography diagnosis and imaging-based management of thyroid nodules: Revised Korean Society of Thyroid Radiology Consensus Statement and Recommendations. Korean J Radiol 2016;17:370-95 CrossRef Medline

32. Alexander EK, Kennedy GC, Baloch ZW, et al. Preoperative diagnosis of benign thyroid nodules with indeterminate cytology. $N$ Engl J Med 2012;367:705-15 CrossRef Medline

33. Marti JL, Avadhani V, Donatelli LA, et al. Wide inter-institutional variation in performance of a molecular classifier for indeterminate thyroid nodules. Ann Surg Oncol 2015;22:3996-4001 CrossRef Medline

34. Nasrollah N, Trimboli P, Rossi F, et al. Patient's comfort with and tolerability of thyroid core needle biopsy. Endocrine 2014;45:79-83 CrossRef Medline

35. Ha EJ, Baek JH, Lee JH. Ultrasonography-based thyroidal and perithyroidal anatomy and its clinical significance. Korean J Radiol 2015;16:749-66 CrossRef Medline

36. Liberati A, Altman DG, Tetzlaff J, et al. The PRISMA statement for reporting systematic reviews and meta-analyses of studies that evaluate health care interventions: explanation and elaboration. PLoS Med 2009;6:e1000100 CrossRef Medline

37. Deeks JJ, Bossuyt PM, Gatsonis C, eds. Cochrane handbook for systematic reviews of diagnostic test accuracy. Version 1.0.0. 2013. The Cochrane Collaboration. http://methods.cochrane.org/sdt/ handbook-dta-reviews. Accessed June 8, 2016

38. Espinosa De Ycaza AE, Lowe KM, Dean DS, et al. Risk of malignancy in thyroid nodules with non-diagnostic fine-needle aspiration: a retrospective cohort study. Thyroid 2016;26:1598-604 CrossRef Medline

39. Jooya A, Saliba J, Blackburn A, et al. The role of repeat fine needle aspiration in the management of indeterminate thyroid nodules. $J$ Otolaryngol Head Neck Surg 2016;45:51 CrossRef Medline

40. Pyo JS, Sohn JH, Kang G. Core needle biopsy is a more conclusive follow-up method than repeat fine needle aspiration for thyroid nodules with initially inconclusive results: a systematic review and meta-analysis. J Pathol Transl Med 2016;50:217-24 CrossRef Medline 